\title{
Design of Web-Based Mini-Games for Language Learning: An Evidence-Based and User-Centred Approach
}

\author{
Jan-Henk Annema ${ }^{1}$, Yorick Poels ${ }^{1}$, Bieke Zaman ${ }^{1}$, and Frederik Cornillie ${ }^{2}$ \\ ${ }^{1}$ CUO, IBBT-K.U. Leuven Future Health Department \\ \{JanHenk. Annema, Yorick. Poels, Bieke. Zaman\} @soc. kuleuven. be \\ ${ }^{2}$ ITEC, IBBT-K.U. Leuven KULAK Future Health Department \\ Frederik.Cornillie@kuleuven-kortrijk.be
}

\section{Introduction}

This paper reports on an ongoing project which aims to develop and evaluate webbased mini-games for language learning in an evidence-based and user-centred approach. In recent years, a shift is taking place towards more learner-centred learning environments, and designers of Computer Assisted Language Learning (CALL) software have stressed the need for a user-centred design approach (Colpaert, 2010; Hémard, 2003). In general, there is a growing interest in participatory design, in which users are involved in the design process (co-design), marking a move away from traditional design methods characterized by an expert mind-set (Sanders 2008).

Many gaming elements, such as competition, interaction/interactivity, problem solving, scoring, and feedback, are also present in traditional learning and testing environments. Hence, it is conceivable that learners' perceptions of these "gaming elements" determine the reception of a language learning activity as a game to a significant extent, rather than the educational intentions of instructional designers alone (Hubbard, 1991). This warrants empirical research on language learners' perceptions of games for learning, as well as user evaluation studies with operational prototypes.

\section{Research Goals}

The study was conducted as part of a project which aims to develop and evaluate web-based mini-games for language learning. Mini-games are small and selfcontained games which usually take a short amount of time to complete and which focus on a specific topic (Frazer et al., 2007). Educational mini-games for language learning seem to favour and even prioritize the development of formal linguistic accuracy. Arguably, language pedagogies nowadays stress communicative outcomes rather than formal linguistic accuracy, partly for motivational reasons. For instance, in the strong communicative approach of task-based language teaching, what matters from the learners' perspective is the communicative outcome of the task (e.g. having compiled a "a story, a list of differences"), rather than the pedagogical aim (whether learners have actually used or apprehended a linguistic structure) (Ellis, 2003, p. 8). 
Our main concern is how educational games can be designed to cater to the needs of the 'net generation' and the 'digital natives'. Since this target group has grown up in a society that is pervaded by technology, and in which technology is an important catalyst of (collaborative) exploration and creativity, this raises questions with respect to the relation of games as a medium of entertainment with, on the one hand, formal/informal learning contexts, and explicitly educational content on the other hand. For the design of educational games for language learning, therefore, it seems critical that a user-centred approach is conducted.

Although the field of CALL has some tradition in developing and researching educational games (Peterson, 2010), what is needed to create language learning games that are foremost a fun and engaging experience for adolescents remains unclear (Purushotma, Thorne, \& Wheatley, 2008). Therefore, we aimed to examine what it is that makes an educational game for language learning engaging and something the learners want to play for the sake of fun alone. Hence, our research question deals with gaining insight into the needs of adolescents concerning fun and engaging educational games for language learning.

We will address this research question from an interdisciplinary perspective that bridges instructional design for second language acquisition with human-computer interaction in order to level sound pedagogy with a coherent, pleasant and meaningful user experience.

\section{Methodology}

To answer our research question, we organized co-design sessions with14- to 16-year-old pupils from general and technical secondary education in Belgium. In these sessions, the participants created game concepts for language learning. In the setup of the co-design session, the mental mechanisms that steer the process of creativity as a cognitive process were taken into account. Consequently, the co-design sessions were structured in consecutive phases that corresponded with the stages that are typical for a creative process: a preparation stage to immerse into the problem, an inspiration stage to arrive at new creative insights, and a transformation stage of evaluation and elaboration (Boden 2003; Bullinger, Müller-Spahn, and Rössler 1996; Csikszentmihalyi 1997; Weisberg 1986). Additionally, we also stimulated the creation of multiple co-design artefacts to improve the design outcomes, exploration, sharing, and group rapport (Dow et al., 2011).

\section{$4 \quad$ Preliminary Results}

The game concepts that were created in the co-design sessions were diverse and demonstrated a range of elaborateness. Two main categories of game concepts could be discerned. On the one hand, there were games concepts in which language was used as a means of communication, while on the other hand, game concepts could be distinguished that focused on formal linguistic learning, e.g. through vocabulary exercises. In contrast with the game concepts in the first category, the concepts in this last category were typical examples of mini-games. This is in line with our expectations that mini-games for language learning seem particularly fit to for the topic of formal linguistic accuracy. 
The game concepts will be analysed further in order to examine in more detail which specific aspects of the make them fun and engaging. The results will then feed into a brainstorm and a specification of user requirements, which both will steer the further design process of mini-games for language learning. In each step of the design phase, in which we will gradually evolve from game concept to low- and high-fidelity prototypes, the same target audience will be consulted at regular times to evaluate intermediate results.

\section{References}

1. Boden, M.A.: The Creative Mind: Myths and Mechanisms, 2nd edn. Routledge (2004)

2. Bullinger, H., Müller-Spahn, F., Rössler, A.: Encouraging Creativity - Support of Mental Processes by Virtual Experience. In: Virtual Reality World. IDG Conferences \& Seminars (1996)

3. Csikszentmihalyi, M.: Creativity: Flow and the Psychology of Discovery and Invention. Harper Perennial (1997)

4. Colpaert, J.: Elicitation of language learners' personal goals as design concepts. Innovation in Language Learning and Teaching 4(3), 259-274 (2010)

5. Dow, S., Fortuna, J., Schwartz, D., Altringer, B., Klemmer, S.: Prototyping dynamics: sharing multiple designs improves exploration, group rapport, and results. In: CHI, pp. 2807-2816 (2011)

6. Frazer, A., Argles, D., Wills, G.: Assessing The Usefulness Of Mini-games As Educational Resources. In: ALT-C 2007: Beyond Control (2007)

7. Hubbard, P.: Evaluating computer games for language learning. Simulation \& Gaming 22(2), 220-223 (1991)

8. Hémard, D.: Language Learning Online: designing towards user acceptability. In: Felix, U. (ed.) Language Learning Online: Towards Best Practice, pp. 21-43. Swets and Zeitlinger, Lisse (2003)

9. Peterson, M.: Computerized Games and Simulations in Computer-Assisted Language Learning: A Meta-Analysis of Research. Simulation \& Gaming 41(1), 72-93 (2010)

10. Purushotma, R., Thorne, S.L., Wheatley, J.: 10 key principles for designing video games for foreign language learning (2009),

http://knol.google.com/k/ravi-purushotma/10-key-principlesfor-designing-video/27mkxqba7b13d/2\#done (retrieved October 22)

11. Sanders, L.: ON MODELING: An evolving map of design practice and design research. Interactions 15, 13-17 (2008)

12. Squire, K.: Cultural Framing of Computer/Video Games. The International Journal of Computer Game Research 2(1) (2002), http: / /www.gamestudies .org/0102/squire/

13. Weisberg, R.W. Creativity: Genius and Other Myths. W.H. Freeman \& Co. (Sd) (1986); Celce-Murcia, M.: Grammar Pedagogy in Second and Foreign Language Teaching. Tesol Quarterly 25(3), 459-480 (1991)

14. Ellis, R.: Task-based language learning and teaching. Oxford University Press, Oxford (2003) 